\title{
PRÁCTICAS Y RESIDENCIAS: MEMORIAS, EXPERIENCIAS, HORIZONTES...
}

\section{Gloria E. Edelstein $\left(^{*}\right)$}

SÍNTESIS: Este artículo aborda un tema nodal de la formación docente, como es la práctica docente. Se habla de ella como una actividad compleja que se desarrolla en escenarios singulares, determinados por el contexto, con resultados en gran parte imprevisibles, y cargada de conflictos de valor que requieren pronunciamientos políticos y éticos. El docente, para llevar adelante esta tarea, debe desplegar su experiencia y su creatividad para afrontar situaciones únicas, ambiguas, inciertas y conflictivas que configuran la vida en las aulas.

Apela a la memoria como un saber de la experiencia, como un movimiento por el cual el sujeto, el docente, reencuentra los sentidos que inciden en su presente, y reconstruye las vicisitudes de un recorrido para hacer visibles zonas de opacidad, para descubrir posibilidades, para abrir brechas.

Interpela a la experiencia de los últimos años en la formación del profesorado como una suerte de retorno reflexivo que permite rescatar el conocimiento aprendido, vislumbrar nuevos caminos y ensayar nuevas propuestas.

En este viaje por las huellas de la formación y por la complejidad de las prácticas docentes, plantea la necesidad de buscar un enfoque teórico metodológico que reconozca los múltiples cruces que se expresan en dichas prácticas. Se trata de un enfoque socioantropológico, en particular de la etnografía en investigación educativa, que coloca el centro de atención en la escuela y en el aula, y que procura diferenciarse de posturas homogeneizantes y universalizantes que no permiten reconstruir la realidad de la escuela como contexto de las prácticas docentes y de la enseñanza. Señala, por tanto, la necesidad de una metodología que permita dar cuenta de los procesos sociales que se materializan en la escuela y en el aula: procesos de apropiación, reproducción, negociación, resistencia, simulación, intercambio, etcétera.

(*) Profesora titular plenaria, Cátedra Práctica Docente y Residencia, Facultad de Filosofía y Humanidades, Universidad Nacional de Córdoba, Argentina. 
SÍNTESE: Este artigo aborda um tema central da formação docente, como a prática docente. Fala-se dela como uma atividade complexa que se desenvolve em cenários singulares, determinados pelo contexto, com resultados em grande parte imprevisíveis, e carregada de conflitos de valor que requerem pronunciamentos políticos e éticos. $O$ docente, para levar adiante esta tarefa, deve estender sua experiência e sua criatividade para afrontar situações únicas, ambíguas, incertas e conflitantes que configuram a vida nas aulas.

Apela à memória como um saber da experiência, como um movimento pelo qual o sujeito, o docente, reencontra os sentidos que incidem em seu presente, e reconstrói as vicissitudes de um caminho para tornar visíveis zonas de opacidade, para descobrir possibilidades, para abrir brechas.

Interpela a experiência dos últimos anos na formação do professorado como um tipo de retorno reflexivo que permite resgatar o conhecimento aprendido, vislumbrar novos caminhos e ensaiar novas propostas.

Nesta viagem pelas marcas da formação e pela complexidade das práticas docentes, nota-se a necessidade de buscar um enfoque teórico metodológico que reconheça os múltiplos cruzamentos que se expressam em tais práticas. Trata-se de um enfoque sócio-antropológico, em particular da etnografia em investigação educacional, que coloca o centro de atenção na escola e na aula, e que procura diferenciar-se de posturas homogeneizantes e universalizantes que não permitem reconstruir a realidade da escola como contexto das práticas docentes e do ensino. Assinala, portanto, a necessidade de uma metodologia que permita dar conta dos processos sociais que se materializam na escola e na aula: processos de apropriação, reprodução, negociação, resistência, simulação, intercâmbio, etcétera.

\section{MEMORIA}

Se trata de un rastreo que permite pensar de nuevo, alcanzar planos de visibilidad respecto de zonas de opacidad, abrir brechas, descubrir posibilidades de movimiento allí donde se imaginaban límites inamovibles; de una relación de conocimiento que remite a un sujeto concreto que ensaya modos de comunicar lo vivido; de la historia de cómo se han institucionalizado criterios de validez, que, a la vez, someten a crítica las autorizaciones, hacen posible revisar lo sabido, identificar marcas, franquear un camino que no sólo procure otorgar unidad y sentido a los diferentes registros, sino que reconozca ejes de problematización, abriendo un espacio para arriesgar otras líneas de tratamiento posible; de narrativas que dan cuenta de trayectos singulares, que, más allá de reconstruir linealmente las vicisitudes de un 
recorrido procurando muestras de un avance constatable, se constituyen en memoria como saber de la experiencia desde la búsqueda de trazos que incluyen el recuerdo de lo imprevisible, la perplejidad, los límites; de un saber en perspectiva que se asienta sobre el relato que enfatiza la presencia insoslayable de la subjetividad, de la contingencia de cada trayecto; de un movimiento en el que el sujeto reencuentra los sentidos que inciden en su presente.

\section{MEMORIA DE EXPERIENCIAS}

Interpelar la experiencia de los últimos años en la formación de profesores significó un doble esfuerzo: seleccionar las cuestiones nucleares que permitieran dar cuenta de una práctica polifacética de intervención en dicho campo, e intentar hacerlo a partir de una exigencia de síntesis impuesta por los límites que plantea ajustarse al tiempo previsto.

Como suele ocurrir ante circunstancias de esta naturaleza, se entremezcla el deseo con una imposibilidad: dar cuenta de un quehacer sin tornearlo, sin violentarlo, pero también la posibilidad de descubrir nuevos sentidos acerca de una práctica, permitiendo su recreación como memoria de experiencia.

En este caso, rememorar lo vivido como movimiento laberíntico propio del retorno reflexivo sobre uno mismo, encuentra un atajo cuando se resuelve en una selección-opción:

- Hablar de algunos aprendizajes, de hallazgos y desarrollos desde el plano conceptual, que resultaron fértiles para vislumbrar nuevos caminos y para ensayar propuestas para andarlos. Decir que se renueva, como invitación a hacer que tales hallazgos se vuelvan cuerpo y lenguaje en las prácticas cotidianas en las instituciones formadoras.

- Compartir viejos y nuevos problemas, que reclaman y desafían la construcción creativa de alternativas de pensamiento y de acción en diferentes ámbitos de la formación de docentes. 


\section{ACERCA DE LO APRENDIDO, LOS HALLAZGOS}

\subsection{AVANZAR EN PRECISIONES AL CARACTERIZAR LAS PRÁCTICAS DOCENTES COMO OBJETOS DE ESTUDIO}

Como ocurre con otras prácticas sociales, la docente no es ajena a los signos que la caracterizan como muy compleja. Tal complejidad deviene en este caso del hecho de que se desarrolla en escenarios singulares, bordeados y surcados por el contexto. Signada por esta impronta, es evidente la imposibilidad de uniformar. En su análisis se pasa de la homogeneidad a la diversidad, de la certeza a la incertidumbre, de los perfiles claros a otros borrosos.

Las determinantes que cruzan y hacen compleja la práctica docente impactan mucho en la tarea cotidiana. Eso hace que esté sometida a tensiones y a contradicciones que provocan, en muchos casos, un corrimiento de aquello que es su tarea central: el trabajo en torno al conocimiento. Por ello, el tiempo permite reconocer que, en los procesos formativos, resulta de interés diferenciar razones que den cuenta de este corrimiento a través de niveles o de escalas diferentes.

Desde un nivel de análisis macrosocial, dichas tensiones remitirían al contexto del cambio y a las paradojas, que, con relación a aquel, se expresan en el marco de la globalización, recuperando aportes de diferentes autores como Hargreaves, Bonafe y Achilli. En tal sentido, cabe referirse al impacto de las condiciones que regulan las prácticas (Bonafe, 1988) desde las políticas, y su expresión en diferentes formas de regulación y de prescripción; a los discursos, como expresión legitimadora de la apropiación social de la práctica, que en gran medida son contradictorios; a las agencias, como instancias organizadoras que determinan los diferentes niveles de concreción curricular, y, en relación con ello, el papel de la administración y el control, la elaboración y la comercialización del material curricular; a la producción de conocimiento pedagógico especializado; a la multiplicidad y diversidad de escenarios que constituyen el contexto espacio-temporal de las prácticas y de las representaciones y significaciones con las que se dota ese contexto. Las culturas y los significados específicos que se producen en relación con esas prácticas, creencias, mentalidades y asunciones arraigadas en los distintos agentes de la comunidad, el mercado y el control sobre la fuerza de trabajo, las fluctuaciones y el valor desigual de cambio en relación con las gradaciones y diferencias en el proceso productivo en la escuela; 
también las resistencias, es decir las formas de respuesta desde el sector docente a la hegemonía.

En este nivel de análisis, cabe aludir también al tipo de organización en que tal práctica se inscribe: surcada por una red burocrática (normativas, prescripciones), parte de una organización jerárquica (en muchos casos todavía ejecutora de decisiones tomadas por otros) enfrentada a la desjerarquización laboral y a una significación social conflictiva [valorización-desvalorización (Achilli, 1988)].

A partir de un registro de otro alcance, se puede advertir que, con frecuencia, se generan representaciones ilusorias que oscurecen el reconocimiento de este quehacer, tales como olvidar el cruce de cuestiones externas al trabajo en el aula, amparadas en la ilusión de autonomía; la idea de atención a las características particulares de los alumnos o del grupo, cuando usualmente se está sujeto a visiones prejuiciosas marcadas por definiciones desde el perfil del alumno ideal; el deseo de trabajar desde un planteo de informalidad, cuando en realidad se trata de una práctica connotada por el peso de la evaluación, donde los docentes, al margen de su conciencia y ante la inmediatez de los acontecimientos, establecen vínculos que reflejan el ejercicio del poder asociado al control, desde el dominio del espacio, el manejo del tiempo, la utilización del lenguaje como instrumento de simulación, la fragmentación y la neutralización del contenido (Remedi, 1988; Becerra, 1989).

Esta última representación sería uno de los sueños más potentes: considerar que, por efecto del compromiso moral que asume y por la valoración positiva de su tarea, puede quedar al margen de las redes en las que se juega el poder, que sólo se ejercería desde esta lectura en espacios ligados a la autoridad formal (la institución, el Estado). El docente despliega su trabajo en un ámbito particular de circulación de poder. Dentro de la red de relaciones que establece con los alumnos, que para mantenerse supone reconocimientos mutuos, se construyen espacios de micropoder y manejos sutiles, donde el nexo saber-poder cobra significativa relevancia.

El desplazamiento de la centralidad del trabajo en torno al conocimiento se vuelve, en ocasiones, condición propiciatoria para que en la vida de las aulas se refuerce esa realidad casi ineludible. Las resoluciones de supervivencia más sencillas en la función, terminan asociándose a la sanción y al control. La falta de problematización deriva 
en la dominancia de rutinas, de viejos modelos internalizados sin criticidad.

¿Qué hacer respecto de tales tensiones y contradicciones? Asumir que se expresan por el entrecruzamiento de rasgos constitutivos de esta práctica, por la referencia a un sujeto social con una trayectoria que ocupa una posición en el interior de las instituciones, ámbitos particulares de despliegue de su actividad profesional. Desde dicha perspectiva, trabajar las huellas de la formación procurando la generación de esquemas de acción alternativos.

La tarea no es sencilla. Es que, al decir de Ardoino, tenemos que ver con sujetos-objetos de conocimiento que casi no pueden construirse, desarmarse, volverse a armar, sin mutilaciones, sin pérdidas. Sujetos caracterizados por lo que se designa como negatricidad, término utilizado para expresar la capacidad de esos sujetos de poder "contestar no" a inducciones, de desbaratar por medio de sus contraestrategias todas las estrategias de las que se sientan objeto. Por ello, cualquiera que sea el trabajo que se realice, siempre subsistirá una parte de opacidad.

De ahí la complejidad de estas prácticas, cuya aprehensión y trabajo de inteligibilidad requieren metodologías alternativas muy distintas de las que ponen en funcionamiento los dispositivos científicos canónicos, y que reclaman una lectura molar, holística y ya no molecular, perspectiva multirreferencial donde la alteración, el conflicto, el juego de las contradicciones ocupen posiciones centrales, y donde lo imaginario y lo inconsciente, la fantasía, la vida afectiva, sobre todo el peso de las implicaciones, no queden separados, solapados en el conjunto de los datos. Así se modifican las relaciones entre implicación y distancia, por paradoja siempre necesarias.

Lejos de ser obstáculos, la implicación y la subjetividad se vuelven modos de acceso a la producción del conocimiento, en cuanto suponen una familiarización progresiva enmarcada en una temporalidad con los objetos-sujetos de conocimiento, buscando una maestría, una habilidad de interiorización-reapropiación y no de propiedad-dominación. 


\section{ANTE ESTA COMPLEJIDAD, CAMBIAR LOS REGISTROS}

\subsection{OTRO APRENDIZAJE IMPORTANTE...}

Profundizar el conocimiento sobre las prácticas docentes caracterizadas de este modo, requiere cambiar los registros y suspender tanto juicios totalizantes como visiones unilaterales. Supone reconocer los múltiples cruces que se expresan en dichas prácticas. Implica la búsqueda de un enfoque teórico-metodológico para abordar su complejidad y problematicidad. En ese sentido se recupera el enfoque socioantropológico, sobre todo de la etnografía en la investigación educativa, desde la relectura que realizan Rockwell y Ezpeleta, enraizada en la tradición antropológica y redefiniéndola.

Tal redefinición, que revaloriza entre otras cuestiones el papel de la teoría articulada con el trabajo de campo, establece una relación diferente entre lo micro y lo macro social, reconoce la necesidad de una postura de pluralismo y de flexibilidad en lo metodológico, y una armonización entre lo objetivo y lo subjetivo en las diferentes instancias del proceso de indagación, tomando distancia de los encuadres antropológicos clásicos (Rockwell y Ezpeleta, 1987).

¿Por qué interesa esta perspectiva? Los centros de atención son la escuela y el aula, escalas para observar-analizar la realidad educativa buscando diferenciarse de posturas que, operando desde una visión homogeneizadora y universalizante, se definen como desviación o ausencia respecto de la norma, sin permitir reconstruir la realidad de la escuela como contexto de las prácticas docentes y de la enseñanza. Se trata, en cambio, de no quedar atrapados en la referencia a atributos formales comunes que impiden dar cuenta de realidades específicas.

En ese marco, se sostiene que la mirada es portadora de una herencia normativo-valorativa que sintetiza categorías heredadas, de los trazos que la historia deja en los sujetos sociales tras largos años de escolarización, que inhibe la apertura a otros registros.

Así se va construyendo un sentido común "académico», que es la lente con la que se acostumbra a mirar la escuela y el aula. Categorías heredadas que no posibilitan dar cuenta de los procesos sociales que en ella se materializan: procesos de apropiación, reproducción, negociación, resistencia, intercambio, simulación, etcétera. 
Tal dinamicidad se constituye en historia no documentada, contraponiéndose con frecuencia a la historia oficial, la de los registros y estadísticas consagrados por la institución. Y es justamente la historia no documentada la que se trata de reconstruir a la luz de este enfoque, y la que sienta sus raíces en la recuperación de lo cotidiano como categoría central, teórica y empírica; aquello que aparece como obvio, fragmentario, recurrente, contradictorio, divergente, con efecto de sentido para los sujetos sociales, aspecto que sólo es posible identificar a partir de indicios que hay que descifrar.

En esta perspectiva se impone una reflexión sobre la relación teoría-empiria, y sobre el papel de quien actúa desde el lugar de indagación. Los sujetos acusan el impacto de determinados fenómenos y los procesan desde sus marcos interpretativos; por ello, se hace imprescindible asumir una actitud de vigilancia permanente sobre los sentidos que construyen desde su lugar. A ese respecto, es necesario ser conscientes de que la realidad puede ser vista desde diferentes prismas, y de que existen diversos patrones de interpretación. Como consecuencia, hay que procurar descentrarse de los propios parámetros y flexibilizar el propio referencial.

Desde este enfoque, la reconstrucción de los procesos por los cuales los sujetos se apropian de las cosas, de los conocimientos, de las costumbres, usos, tiempos, espacios, relaciones y reglas de juego, admiten la descripción de tramas de evidencia diversa.

Por cierto que una lectura de esa naturaleza demanda una sustancial modificación de las pautas de trabajo más extendidas respecto de la observación y el análisis de prácticas docentes, sobre todo despegarse del cruce evaluativo, que en muchos casos las caracterizan. Apoyarse en procesos de reflexión no exentos de intencionalidad, que, superando posiciones objetivistas que acentúan la rigurosidad de las descripciones, se interesen en especial por encontrar nuevos caminos y formas de acceso a las situaciones objeto de estudio. Ello reclama apelar a una posición reflexiva permanente, lo que implica una particular sensibilidad teórica y metodológica tanto en el investigador como en los sujetos comprometidos en las situaciones objeto de indagación, a partir de entender que los procesos de conocimiento y de comprensión inciden de manera directa en las propuestas de intervención. 


\section{ACERCA DE LOS PROBLEMAS}

\subsection{RESPECTO DE LOS ESPACIOS DE LA PRÁCTICA}

\subsubsection{Nominación e identidad}

Los espacios de la práctica son formas de nominación y de designación, cargadas asiduamente de ambigüedad, que, por tanto, no otorgan referentes claros. ¿Qué efectos producen en los sujetos a cargo, por encargo de los mismos? Al interrogar y problematizar tal situación, resultan de valor algunos aportes de Bourdieu sobre el tema, mediados por la propia significación de sus ideas.

A través de la forma singular de nominación que constituye el nombre propio, se instituye una identidad social constante y duradera que garantiza la individualidad de la persona en todos los campos en los que interviene. El nombre propio se desgaja del tiempo, del espacio y de las variaciones, según los lugares y los momentos. Garantiza a los individuos designados, más allá de los cambios y de las fluctuaciones, la constancia nominal, la identidad en tanto especificidad que requiere el orden social. Designador rígido, el nombre propio es la forma por antonomasia de la imposición arbitraria que llevan a cabo los ritos instituidos. El nombre propio es soporte, atributos y atribuciones; descripción oficial y certificado que garantiza de forma irreversible una capacidad (o una incapacidad). Sin embargo, tratar de comprender una vida como serie única y suficiente de acontecimientos sucesivos desde la sola constancia de un nombre propio, sería absurdo para Bourdieu. Se requiere incorporar la noción de trayectoria como serie de posiciones ocupadas por un mismo agente (o un mismo grupo) en un espacio en sí mismo en movimiento y sometido a incesantes transformaciones (Bourdieu, 1997).

Cabe advertir entonces la necesidad de un movimiento que, a la vez que problematiza, relativiza el nombre propio y reconoce su valor de referencia frente a la ambigüedad. Se trata de un conjunto de ideas que quizás podrían abrir puntos de indagación con respecto a la configuración de los espacios de la práctica; más aún, si la indagación amplía el punto de interrogación en procura de analizar el lugar, como lugar social, de estos espacios en el campo de la formación como campo social. 
Aquí también resultan fértiles los aportes de Bourdieu en su análisis sobre los campos sociales, espacios de juego históricamente constituidos con sus instituciones específicas y sus leyes de funcionamiento propias; campos que se definen por lo que está en juego, por los intereses y compromisos específicos, por las apuestas que en tanto producto histórico engendran y activan, y que se constituyen en condición de su propio funcionamiento; campos que se estructuran por el capital en juego en un momento dado (capital económico, cultural, social, simbólico), que otorga reconocimiento, consagración, prestigio, distinción, autoridad, legitimidad, que implica relaciones de fuerza entre los agentes o las instituciones comprometidas en el juego; por ende, campos de lucha dinámicos, por lo que se definen y redefinen históricamente, redefinición respecto de la cual no puede establecerse una causalidad única, y que puede devenir de la propia lógica interna o deberse a la incidencia de factores externos al campo específico. No se pueden desligar los actos de pensar de las condiciones sociales de producción de conocimiento. He aquí un interesante punto de interrogación-problematización.

Desde otro ángulo que puede resultar interesante rescatar, cabe reconocer cómo en el proceso por el cual las disciplinas (como campos de conocimiento) se hacen autonómicas, marcan sus fronteras y las legitiman, se van generando -hasta que se normativizan- las prácticas rutinarias de asunción de comportamientos específicos, lo que genera en los sujetos cierta identidad que conlleva la imposición y la aceptación de percepciones, valoraciones, derechos y obligaciones no menos específicos. Los subuniversos simbólicos de significado propio de cada disciplina generan no sólo formas de legitimidad particularizadas, sino que inciden en la legitimación de los sujetos según los papeles que desempeñen. En tanto la identidad se construye en virtud de la existencia de la alteridad, de lo otro, la identidad disciplinaria es también de oposición.

De hecho, las distintas disciplinas conforman modos de exclusión que operan a partir de un trabajo hacia su interior. Así mismo, se observa un disciplinamiento de los sujetos, en el sentido de que deben someterse a las formas de control que se establecen en cada caso, y, entre otras, a las reglas del discurso imperantes, que, a su vez, está monitoreado desde los límites y los márgenes de su propio territorio, lo que se ha traducido en una creciente cristalización de tales espacios.

Estas versiones construidas desde las disciplinas, que en el currículo tienen su traducción en las asignaturas, se extrapolan con 
demasiada frecuencia al plantear en los diseños espacios que remiten a diferentes disciplinas. Los nuevos currículos para la formación docente estarían abriendo curso a una oportunidad. El problema reside en cómo aprovechar dentro de estos espacios los aportes de profesionales formados en distintas disciplinas, que, por ello, pueden llevar a cabo convergencias relacionales innovadoras con una fuerte intensidad explicativa y una novedosa capacidad heurística. ¿Cómo hacer de esto la vía principal de autorización, de legitimación de los espacios de la práctica en los planes de formación de docentes? ¿Cómo aprovechar paradójicamente, en sentido de potencialidad, la marca de ambigüedad desde la nominación?

\subsubsection{Una construcción interdisciplinaria}

Tal vez no surjan dudas en cuanto a que estos espacios requieren una construcción interdisciplinaria. De ahí que resulte atinado revisar los debates sobre el tema. Hoy se cuestionan sin timidez los seguros caminos del conocimiento. La incertidumbre no es una palabra de moda, es un signo que pone en tela de juicio esta seguridad. El reto no es simple; se han hecho más complejos los objetos de conocimiento, al tiempo que se ha abierto la búsqueda de nuevos caminos, de maneras de abordar y de comunicar saberes en discusión. Pareciera ser, al decir de María Saleme, que ya no se trata de sumar conocimientos provenientes de campos distintos desde una hiperespecialización, sino sencilla y dificultosamente religar conocimientos organizándolos con sentido integrador. No se trata de desestimar la unidad del objeto, tal como lo abordan las disciplinas; sin embargo, ya no es posible desentenderse de su ser multifacético como se constituye desde la interdisciplina (Saleme, 2000).

La naturalización del conocimiento operada por el sentido común no actúa sólo como un bloqueo epistemológico en el plano de desarrollo de las ciencias, lo hace en la inercia de las instituciones de enseñanza como un bloqueo en la relación con el conocimiento. La disciplina, en este sentido, es también víctima de la saturación del encierro. La ruptura que en un momento de su historia permite desbloquear al conocimiento de sentido común, se convierte, según Facundo Ortega, en ese segundo sentido común, el disciplinario, que limita el horizonte del descubrimiento. La interdisciplina presupone la fragilización de los campos en los que se constituyen las disciplinas, implica duplicar las dudas, ya no sólo internas sino reflejas, pero también volver a una 
divulgación científica de las ciencias, a una narración que permita abrir los límites de éstas.

Desde la convergencia multidisciplinar -y esto se expresa como tendencia en la producción de conocimientos- comienzan a instituirse regiones, campos en los que se traducen las disciplinas básicas a un nuevo código interno. Se genera así un cruce de disciplinas, que, sin llegar al trabajo interdisciplinario, crea un código propio y un ámbito de prácticas y de investigaciones que se actualiza siempre a través de la traducción al código propio de las transformaciones de otros campos disciplinarios, sin poder desarrollar un corpus de conocimiento autónomo, es decir, capaz de promover procesos de conocimiento desde adentro. No por ello dejan de producir caparazones cognitivos, haciendo de aquella dinámica un fenómeno que no se diferencia en cuanto a las prácticas de autorreferencialidad característica de las disciplinas.

Asistimos a una reconfiguración del pensamiento social, a un nuevo trazado de fronteras, a una nueva cartografía de las disciplinas sociales (Geertz, 1996). Se comienzan a desarrollar espacios de conocimiento limítrofes, en los que las fronteras de una disciplina se confunden con las de otras. El desarrollo de estos espacios comunes implica la ampliación del campo disciplinario, a la vez que la superposición con otros campos; moviliza un proceso complejo en el que interactúan dos o más campos disciplinares, con desarrollos e identidades dispares. También se asiste al surgimiento de nuevos objetos y de nuevos problemas, estricto sentido del término interdisciplina. Nuevos objetos nunca considerados antes, nuevas miradas sobre objetos, nuevos problemas analizados con métodos y técnicas de larga tradición en otros campos.

En este aspecto interesa destacar que sólo a partir del reconocimiento de la diferenciación puede evitarse la tendencia a un conocimiento que, en su pretensión omnímoda, no podría ser otra cosa que una mezcla indiscernible de perspectivas y de niveles de análisis que requieren ser discriminados. En esta perspectiva cabe pensar en acercamientos tentativos, en ensayos, en voluntad que propone -a partir de intereses específicos- los criterios desde los cuales la conexión interdisciplinar se haga posible. Y es desde esta contingencia asumida que lo interdisciplinar se revela como autorizable y como deseable y necesario.

En el marco de dichos debates, resulta de interés destacar que interpretaciones actuales de la interdisciplina han abandonado la idea de unidad del conocimiento, y buscan la articulación de sectores acotados 
del saber. Se trata, al decir de Follari, de una interdisciplinariedad local, no global, desechando la búsqueda de grandes síntesis. Desde esta redefinición de la noción, se desconfía de la posibilidad de ciencia unitaria y de los principios racionalistas, generalizantes y normativos que la sustentaron.

El trabajo interdisiciplinario reclama asumir la práctica de una convivencia aceptable con el otro disciplinado, de modo que se puedan comprender las respectivas lenguas, tarea nada sencilla si tenemos en cuenta que dicho aprendizaje demanda años de estudios disciplinantes, esfuerzo justificado si se admite que estas búsquedas devienen de los fuertes cuestionamientos a los núcleos duros de los espacios disciplinarios tradicionales, que, entre otras cosas, han puesto en evidencia la fragilidad y la arbitrariedad de la cartografía que habían construido.

\subsection{RESPECTO DE LAS RESIDENCIAS}

\subsubsection{La doble inscripción institucional de las propuestas}

La entrada en las instituciones educativas para la Residencia pone en juego múltiples relaciones: vínculos entre instituciones, con historias y trayectorias diferentes; vínculos entre sujetos sociales cuya pertenencia los coloca en lugares que portan significados también diferentes. Ello implica el desarrollo de propuestas en un espacio social, cuya conflictividad interroga la responsabilidad de formadores respecto de los efectos de la experiencia tanto en instituciones como en sujetos involucrados.

Significada de este modo, la relación conlleva disposición para operar en variabilidad de situaciones, de contextos, de instituciones, de culturas. Desde allí, asumir un trabajo colaborador con el desafío constante de reconocer y de respetar la diversidad. Para ello, poner en suspenso posiciones de asimetría, abrir a un diálogo de pares, hacer posible desde espacios deliberativos, reflexivos y críticos el compartir y construir nuevos conocimientos.

La co-construcción supone la interacción social con otros. Remite a una fuerza contextual y a una fuerza implicatoria. Articuladas dialécticamente, quizás permitan imaginar situaciones en las que las acciones tengan suficiente fuerza implicatoria como para cambiar el contexto en que suceden. 
Coincidiendo con Connelly y Clandinin, de lo que se trata es de construir comunidades de atención mutua en las que todos los participantes se vean a sí mismos como miembros de una comunidad con propósitos compartidos. Eso implica mejora en las disposiciones y capacidades, sobre la base de compromisos recíprocos que se construyen en los mismos procesos de trabajo, que no son a corto plazo. A los participantes les lleva tiempo reconocer el valor de apostar a la relación, que implica sentimientos de conexión que se desarrollan sólo en situaciones de igualdad, de atención mutua y de propósitos e intenciones compartidos. Implica prestar atención a la forma de situarse en la relación con otros, ya que los participantes modelan en sus prácticas una cierta valoración y confirmación mutua. Se impone entonces la necesidad de tiempos, de espacios y de voz; de hablar por uno mismo y de sentirse oído por otros, voz que sugiere vínculos: los del sujeto con el sentido de su experiencia

Se trata de un juego de creencias, de una forma de trabajar que exige conocimiento conectado, de un juego de creencias que conlleva un proceso de autoinserción en la historia del otro. Conocer esa historia es dar voz al otro, contexto experiencial en el que se reflexiona sobre vivencias procurando explicarlas a otros. Un clima adecuado requiere un delicado giro $m$ entalen los participantes, una particular sensibilidad que haga posible que se reajusten horizontes tem porales, sociales y culturales.

Sin em bargo, las form as anaigadas de pensar, de deciry de hacer en los ám bitos educativos, todavía no son propiciatorias de tales propósitos a raíz de viejos m odelos intemalizados, porque las estrategias de implem entación de las políticas de reform a en las instituciones form adoras han hecho que éstas se sientan m uy am enazadas en su subsistencia, con la consecuente pérdida de identidad que de ello se deriva, dando lugar a clim as propicios para el resurgim iento de individualism os y de form as balcanizadas en la concreción del trabajo cotidiano, rasgos conporativos y com petitivos antagónicos con cualquier pretensión, aunque sea incipiente, de construcción solidaria. En tal sentido, el desafí sigue consistiendo en procurar y provocar tiem pos y espacios que perm itan poneren cuestión m atrices construidas, trabajar huellas y $m$ arcas de largos años de escolanización, recuperar lo m ejorde las trayectorias colectivas e individuales, adm itir la urgencia de ciertos cam bios, e intentar cam inos diferentes. 


\subsubsection{El énfasis en la observación-evaluación sobre la construcción de conocimientos}

Las Residencias plantean un problema sustantivo: despejar el énfasis del cruce evaluativo que signa las propuestas como sello que parece inevitable ante la fuerza del valor social de la acreditación. Pasar a un planteo en términos diferentes implicaría admitir que constituyen un momento privilegiado para compartir y para construir conocimientos ligados a las prácticas profesionales que no se puede perder. Eso significa apostar por la especificidad formativa de dichos espacios.

El papel históricamente asignado a la observación en los procesos de Residencia no ha sido propiciatorio para un marco que permita concretar este propósito. Quebrar la fuerza de tal nexo supone distancia con la observación, ligada a la vieja idea de crítica pedagógica, al énfasis en conductas observables, en parámetros y en categorías predefinidas. El valor instrumental asignado a las planillas-grillas las convierte en guías de observación, no sólo aquellas objetivables desde su materialidad impresa en un esquema, sino las grillas interiorizadas, más sutiles en sus efectos.

Admitir que en la observación se juega la mirada de un otro autorizado, adquiere un poder asociado al poder de dominación; de ahí su eficacia como dispositivo que otorga visibilidad desde un lugar significado, como de supervisión, que se asocia a la vigilancia, al control y a la sanción. Pasar a observar para conocer, conocer para comprender, donde la observación sea entendida como medio para obtener información y como proceso para producir conocimientos. Ello requiere observar la observación, objetivar el propio lugar, reconocer la no neutralidad, admitir que mirar se hace desde pequeñas hendiduras, y que mucho del territorio del otro queda fuera de las inquisiciones de la curiosidad, operación que reduce sentidos, en tanto registra aquello que puede ser visto y oído. Encuentro de miradas de los sujetos, que, en realidad, debiera intermediarse por el objeto que los reúne, centrando el foco en la cuestión del conocimiento, y triangulando la relación que demanda trabajo para sostener como centro el vértice pertinente en cada caso.

Desde esta perspectiva, la evaluación en el marco de las Residencias conduciría a poner en el centro la propuesta de enseñanza concebida holísticamente como punto de referencia, a incorporarla en función de acreditación y como un analizador que permite reconocer los recorridos, los movimientos que cada sujeto va realizando en la genera- 
ción de la propuesta para las prácticas. Superar la apuesta individual a parámetros de excelencia posibilitaría rastrear la diversidad en los procesos, en los estilos y en modalidades de avance singularizados. En todo caso, el formador sólo marca momentos y apuesta por concretar desde una posición de ayuda las mejores producciones posibles en cada situación. Se trata de un desplazamiento impostergable, de girar el foco de atención de la observación-calificación a la construcción de conocimientos acerca de las prácticas de la enseñanza.

Nuevos enfoques de la evaluación en los centros de formación podrían dar lugar a un alto potencial generador de nuevos habitus desde la formación inicial de grado, que pudieran al menos marcar una huella en la actuación profesional futura.

\section{POR FIN, HORIZONTES...}

Es necesario superar la explicación, pensar fuera de los límites de una concepción preestablecida, fortalecer la capacidad de apertura crítica que pueda traspasar las estructuras cosificadas del saber-información, reemplazar la idea de parámetro por la de potencial, reconocer los horizontes que no se circunscriben a la lógica de las conceptualizaciones ya formalizadas.

Descubrir la potencialidad no confina el pensamiento a estructuras que tienden a reificarse. Su rasgo esencial radica en confrontar el pensamiento con las múltiples posibilidades de concreción. Trascender la organización de una estructura racional fija, y reemplazarla por una forma de razonamiento de categoría abierta, fundada en relaciones posibles, en espacios articuladores; no en verdades absolutas sino en construcciones posibles. Transformar el horizonte histórico en conocimiento. Captar la dinámica constitutiva de una realidad, que significa el reconocimiento de opciones y la necesidad de asumir y de lanzarse a la apuesta de aquellas opciones que se asuman como propias.

El pensamiento complejo no es, según señala Morin, el omnisciente. Por el contrario, es el que sabe que siempre es local, ubicado en un tiempo y en un momento. Sabe de antemano que hay incertidumbre. Por eso escapa al dogmatismo arrogante que reina en los pensamientos no complejos. Sin embargo, no cae en un escepticismo resignado, 
porque, operando una ruptura total con el dogmatismo de la certeza, se lanza a la aventura incierta del pensamiento

En la ruptura de la coherencia entre nuestras teorías y su relación con las realidades de las que somos parte, es donde se hace notable la insuficiencia de las fórmulas aprendidas. En esas bifurcaciones, según Schnitman, recreamos matrices para la creación. La sorpresa se torna útil, porque nos permite reflexionar acerca de lo que damos por supuesto, acerca de lo obvio, de lo evidente. Emerge como un mundo desconocido que interactúa con aquél en el que estábamos existiendo. Se pierde la ilusión de una narrativa o de un tipo de discurso capaz de proveer un guión unitario, pero surgen perspectivas que proponen capturar la fragmentación, la pluralidad, las diferencias, la multidimensionalidad en diseños complejos de las relaciones humanas y de la subjetividad, que se apoyan en redes intraintersubjetivas con múltiples focos. Esta perspectiva conduce a un modo no secuencial de pensamiento-acción, que, al desgajar las certezas, gana en nuevos y más ricos interrogantes. El desafío consiste en explorar las posibilidades, de modo que los interrogantes de estos tiempos se vuelvan instrumentos para la creatividad, en concebir nuestra profesionalidad en términos de promotores de alternativas nuevas, como artesanos de contextos y de contextos de contextos (Schnitman y Fuks, 1995).

Eso implica restituir a los docentes un saber profesional sólido y actualizado, que tiene que ver con su propia identidad y especificidad, y del cual han sido despojados; bregar por el acceso individual y colectivo al saber y al saber hacer especializado; hacer valer un código ético en el ejercicio de la profesión, y, por tanto, la participación responsable e informada en los espacios y procesos de discusión y de toma de decisiones que competen a su tarea.

En esta perspectiva, coincidiendo con Dussel, necesitan acceder a saberes renovados y plurales, estar en contacto con instituciones y con sujetos productores de conocimientos, de modo que puedan abrirse a la cultura y al conocimiento como mundos complejos. Eso significa recomponer, recrear, reformular los vínculos de los docentes con la cultura, pero no desde su exclusiva responsabilidad individual, sino desde un movimiento social a partir del cual se rejerarquice su papel en la producción y transmisión de la cultura de la que forman parte, significada como producto de dinámicas históricas y de luchas sociales (Dussel, 2001). 
Para terminar, quisiera compartir un texto de Morin, que dice: «No se trata aquí de oponer la experiencia vivida a la abstracción teórica [...] se trata de enriquecer a unas y otras haciendo que se comuniquen [...] es preciso pues, abrir una brecha en las clausuras territoriales, renunciar a los exorcismos y las excomuniones, multiplicar intercambios y comunicaciones, para que todas estas andaduras hacia la complejidad confluyan, y para que por fin podamos concebir no sólo la complejidad de toda realidad sino la realidad de la complejidad».

\section{BIBLIOGRAFÍA}

ACHILLI, E. (1986): La práctica docente: una interpretación desde los saberes del maestro, Buenos Aires, CRICSO.

AGENO, R. (1989): «El taller de educadores y la investigación», en Cuadernos de formación docente, Rosario, Universidad Nacional de Rosario.

BecerRa, M. G., Garrido M. R. y Romo R. M. (1989): «De la ilusión al desencanto en el aula universitaria. Una panorámica áulica del curriculum», en Desarrollo de la investigación en el campo del curriculum, México, UNAM.

Bolivar, A. (1995): El conocimiento de la enseñanza. Epistemología de la investigación del curriculum, FORCE, Universidad de Granada.

BoURDIEU, P. (1997): Razones prácticas. Sobre la teoría de la acción, Barcelona, Anagrama.

BOURDIEU, P. y WAQUANT, L. J. D. (1992): Réponses: pour une anthropologie réflexive, París, Seul.

DucoIng WATTY, P. y RodRIguez OUSSET, A. (comp.) (1990): Formación de profesionales de la educación, UNESCO/UNAM, México, D.F., ANUIES.

EDELSTEIN, G. (2000): «El análisis didáctico de las prácticas de la enseñanza. Una referencia disciplinar para la reflexión crítica sobre el trabajo docente», en Revista del Instituto de Investigaciones en Ciencias de la Educación (IICE), Año IX, núm. 17, Facultad de Filosofía y Letras, Buenos Aires, Miño y Dávila.

EDELSTEIN, G., y CORIA, A. (1995): Imágenes e Imaginación. Iniciación a la docencia, Buenos Aires, Kapelusz.

GORE, J. M. (1996): Controversias entre las pedagogías, Morata, Madrid.

LARROSA, J. et al. (1995): Déjame que te cuente. Ensayos sobre narrativa y educación, Barcelona, Laertes. 
LISTON, D. P. y ZEICHNER, K. M. (1993): Formación del profesorado y condiciones sociales de la escolarización, Morata, Madrid.

PÉREZ GÓmEZ, A. (1993): «Autonomía profesional y control democrático», en Cuadernos de Pedagogía núm. 220, monográfico: El Profesorado, Barcelona, Fontalba.

REMEDI, E. et. al. (1987): La identidad de una actividad. Ser maestro, México, DIE-CINVESTAV-IPN.

Saleme de Burnichon, M. E. (1997): Decires, Córdoba, Narvaja Editor.

SALEME DE BURNICHÓN etal. (2000): Interdisciplina, Publicación del CIFFYH, año 1, núm., Facultad de Filosofía y Humanidades, UNC.

SALINAS FERNÁNDEZ, D. (1994): «Reflexión del profesor: la novedad de un viejo principio», en Cuadernos de Pedagogía, núm. 226, Barcelona, Fontalba. Aires, Paidós.

SCHNITMAN, D. F. (1995): Nuevos paradigmas, cultura y subjetividad, Buenos

SCHÖN, D. (1992): La formación de profesionales reflexivos. Hacia un nuevo diseño de la enseñanza y el aprendizaje en las profesiones, Madrid, Paidós.

WitTRock, M. C. (1989): La investigación de la enseñanza. Enfoques, teorías y métodos, Barcelona, Paidós. 


\title{
Contactar
}

Revista lberoamericana de Educación

\author{
Principal OEI
}

